\title{
ANÁLISE DE UMA ORGANIZAÇÃO FAMILIAR À LUZ DO MODELO MULTIDIMENSIONAL-REFLEXIVO
}

\author{
I. N. FERRAZ ${ }^{* 1}$, H. S. B. CAVALCANTI JUNIOR ${ }^{2}$ e M. N. FERRAZ ${ }^{2}$ \\ ${ }^{1}$ Universidade de Brasília (UnB) \\ ${ }^{2}$ Universidade Federal de Pernambuco (UFPE) \\ isabelanf@unb.br
}

Artigo submetido em abril/2013 e aceito em setembro/2015

DOI: $10.15628 /$ holos.2015.1390

\section{RESUMO}

O principal objetivo deste trabalho consiste em analisar, a partir da realização de um estudo de caso, uma organização familiar, tendo como referência o Modelo Multidimensional-Reflexivo de Alves (2003). Todos os característicos retratados no presente artigo, obtidos através da pesquisa documental, entrevistas e observação não-participante, e analisados por meio da técnica de análise de conteúdo, permitiram, como principal achado, o enquadramento da empresa familiar analisada como uma organização, de fato, equiparativoadaptadora, à luz do modelo formulado por Alves (2003).

PALAVRAS-CHAVE: Organizações, Empresas familiares, Modelo Multidimensional-Reflexivo.

\section{ANALYSIS OF A FAMILY ORGANIZATION BASED AT THE MULTIDIMENSIONAL- REFLECTIVE MODEL}

\begin{abstract}
The main objective of this work is to analyze, from a case study, a family organization, with reference to the Multidimensional-Reflective Model of Alves (2003). All characteristics portrayed in this article, obtained through desk research, interviews and non-participant
\end{abstract}

observation, and analyzed by the technique of content analysis, allowed as main finding the framing of the family company analyzed as an organization, in fact, equate-adapter to the light of the model formulated by Alves (2003).

KEYWORDS: Organizations, Family businesses, Multidimensional-Reflective Model. 


\section{INTRODUÇÃO}

As organizações familiares constituem espaços produtivos importantes no cenário econômico. Assim como os demais arranjos empresariais, esses espaços buscam principalmente conseguir uma atuação eficiente para operar competitivamente diante da concorrência, com a particularidade de trazer em si as especificidades das inter-relações e do convívio familiar.

Esse tipo de empresa define-se como uma entidade em que, no mínimo, há duas gerações, tem a sua origem e história relacionada a uma mesma família ou possuindo pessoas de uma mesma família no controle e administração do negócio (GRZYBOVSKI; TEDESCO, 1998). O Brasil é um país em que desde pequenas empresas até as grandes organizações existentes, e que não são estatais, são classificadas como familiares, a exemplo de corporações como a Gerdau, o Grupo Votoratim e o Pão de Açúcar (TOSO JUNIOR et al., 2010). Segundo esses autores, tais estruturas funcionam como referência na sociedade, impactando diretamente nos segmentos econômicos do país e exercendo papel fundamental na geração de empregos e aquecimento do mercado empresarial.

As empresas familiares são heterogêneas entre si, variando quanto ao tamanho e nível de competitividade dentro do ambiente em que se inserem. Porém, mesmo possuindo as suas diferenças, algo que emerge como fonte de preocupação em todas as corporações familiares, refere-se à sua sobrevivência, o que engloba fatores como a sucessão, a gestão profissional e a abertura de capital (LETHBRIDGE, 1997). Essas são questões comuns e que caracterizam uma situação compartilhada pelas organizações de base familiar em todo o mundo.

A sobrevivência da empresa familiar está relacionada às dificuldades de sucessão, que configuram um forte obstáculo à perpetuidade dessas organizações e representam um dos principais motivos de seu declínio. O processo sucessório faz com que esteja em jogo contínuo as interações entre família e trabalho, cujos conflitos podem incidir sobre o seu funcionamento e rumos, no sentido de sua expansão ou até mesmo de seu declínio (CAMPOS; MAZZILLI, 1998). De acordo com Antonialli (1998), para conseguir garantir a sobrevivência da organização familiar, é fundamental a habilidade dos membros da família em exercer a sua administração e conseguir evitar os problemas derivados da sucessão. Apesar de poder atuar como um fator restritivo, a sucessão não necessariamente deverá ser sempre vista como algo negativo para a empresa. Uma gestão eficiente e capaz de se planejar para enfrentar situações como essa, conseguirá manter a organização tão empreendedora e competitiva (ou às vezes até mais) quanto antes, garantindo a sua permanência no mercado.

Além da dificuldade da sucessão, segundo Soares, Machado e Marocco (1997), outras barreiras podem surgir em relação aos complexos familiares, a exemplo do fato da própria gestão em família tornar-se um empecilho ao estabelecimento de funções, direitos e deveres de seus membros, tanto no sentindo de favorecer a ascensão deles, quanto de permitir que fiquem impunes no caso de desobediência às regras. Conflitos em família e uso da estrutura organizacional para fins particulares também são limitantes que podem ser enfrentados nessas estruturas. Por outro lado, as autoras também observaram os pontos fortes que são resultantes de um arranjo familiar, dentre os quais se encontram: maior liberdade de opinião, comprometimento e agilidade nas tomadas de decisão; maior capacidade para suportar as 
dificuldades enfrentadas pela empresa; melhores condições de se estabelecer com os clientes fortes relações de credibilidade confiança e continuidade. Cabe, portanto, a uma gestão eficiente, a competência de conseguir minimizar os pontos fracos e maximizar os pontos fortes da empresa.

Todos os percalços e conveniências existentes nas empresas familiares demonstram a complexidade de tais estruturas e a necessidade que se faz de uma melhor compreensão de sua dinâmica interna e da sua relação com o ambiente no qual atuam. É necessário um modelo de análise que consiga absorver as peculiaridades encontradas numa organização familiar.

Um dos modelos que poderia servir em investigações dessa natureza é o Multidimensional-Reflexivo, proposto por Alves (2003), por conseguir trazer categorias analíticas que vão além da burocrática. Além disso, o modelo caracteriza-se por apresentar as seguintes características: oferecer uma abordagem organizacional através da ótica da sociologia weberiana, visualizar mais apuradamente o ambiente interno e colocar em evidência a estrutura e o agente individual como dimensões articuladas e que se influenciam mutuamente (CORREIA, 2007). Acredita-se, assim, que o Modelo Multidimensional-Reflexivo é o construto adequado para análise de empresas familiares, auxiliando na compreensão de suas relações internas e com o ambiente.

O principal objetivo deste trabalho consiste em analisar uma organização familiar, através da realização de um estudo de caso, tendo como referência o Modelo MultidimensionalReflexivo de Alves (2003). Há que se entender o alcance desse objetivo como mais uma contribuição ao estudo da unidade produtiva-empresarial de base familiar em Pernambuco, já que se procura examinar atentamente os indicadores trazidos por Alves (2003) - ambiente e relações interempresariais, características estruturais e dispositivos de coordenação, características do agente e relacionamentos internos, natureza das tarefas e sistema técnicooperacional da organização -, bem como identificar as aproximações ou distanciamentos da organização estudada (real) em relação às tipologias trazidas pelo modelo de Alves (2003).

\section{REVISÃO BIBLIOGRÁFICA}

\subsection{O Aporte Weberiano}

De acordo com Alves (2003), a concepção de tipo ideal é algo básico dentro da corrente epistemológica de Weber, representando uma construção parcial da realidade, na qual o pesquisador escolhe um determinado número de características, destaca o(s) elemento(s) observado(s), e tem como resultado a edificação de um todo inteligível. Vale salientar que o tipo ideal weberiano serve apenas para representar as características de instituições ou comportamentos que fazem parte de uma sociedade, sem ter a pretensão de representar algo que "deve ser", que é "melhor" ou "exemplar".

Outra contribuição weberiana de extremo valor para a análise sociológica refere-se à elaboração de uma taxonomia de ação social que põe em relevo a forma pela qual as ações dos indivíduos são realizadas. A distinção dos quatro tipos de ações sociais foi feita por Alves (2003). Vejamos. 
- A ação racional no tocante aos fins - é o tipo de ação que envolve uma racionalidade instrumental, funcional ou técnica, em que o indivíduo orienta a sua ação de forma consciente e calculada.

- A ação racional com relação a um valor - envolve uma ação que é ditada pelo valor que a determina, assim, o significado que é dado a ação torna-se maior do que a consciência das suas consequências.

- A ação afetiva - é a ação que é determinada pelos laços emotivos existentes entre os indivíduos, sendo caracterizada pelo sentimentalismo existente em uma dada circunstância.

- A ação tradicional - manifesta-se por meio de uma ação que é ditada pelos costumes consagrados ao longo do tempo, não havendo intencionalidade envolvida no ato.

A forma pela qual as ações são conduzidas por seus agentes permitem a observação de dois conceitos essenciais na visão sociológica weberiana: o poder e a dominação. A dominação, na percepção de Weber (1999), é um dos elementos mais importantes da ação social, já que todo ato executado por indivíduos apresenta uma estrutura que implica em dominação. Weber (1999) compreende a dominação como uma situação em que a vontade manifesta do dominador, ou dos dominadores, irá influenciar a ação de outras pessoas, conhecidas como dominados. Essas ações são influenciadas de tal forma, que se concretizam "como se os dominados tivessem feito do próprio conteúdo do mandado a máxima de suas ações" (WEBER, 1999, p. 191). Já o poder, segundo o pensador, revela-se como um conceito marcado pela imprecisão, em que um conjunto de interesses pode colocar determinado indivíduo numa posição em que o mesmo seja capaz de impor a sua vontade perante os outros.

A diferença básica entre os conceitos de poder e dominação manifesta-se no sentido de que, no caso do poder, a obediência não se manifesta como um dever; já na dominação a obediência tem como referência o reconhecimento da legitimidade por parte daqueles que obedecem às ordens dadas (ALVES, 2003). A dominação, na abordagem weberiana, encontra-se relacionada à administração, configurando-se por meio dos três tipos trazidos por Weber (1999): a dominação patriarcal, a dominação carismática e a dominação burocrática. Cada um desses tipos de dominação são descritos, na visão de Weber (1999), a seguir.

A estrutura patriarcal de dominação é qualificada pelo autor no status do mais importante dos princípios estruturais pré-burocráticos. Sua base encontra-se em relações de piedade rigorosamente pessoais, e sua origem, na autoridade do chefe da comunidade doméstica (aludindo à família, em situação em que o pai ou o herdeiro masculino de sua escolha exerce o domínio sobre os demais membros do agrupamento de indivíduos). Assim, a dominação patriarcal é, rigorosamente, a submissão ao senhor, fato que garante a legitimidade das regras por ele estatuídas e que são sagradas pela tradição. Deve existir entre senhor e submetidos uma relação de reciprocidade, que esteja de acordo com o costume. A dominação patrimonial, em particular, perfaz um caso específico da estrutura patriarcal em que se tem uma forma de organização com raízes fincadas na comunidade doméstica patriarcal, com o poder descentralizado, mediante a partilha de bens a descendentes ou outros indivíduos que gravitam no círculo que se forma em torno do chefe, do patriarca, e que deste dependem. 
A dominação carismática é expressão que ao abranger a adjetivação carismática, indica um tipo particular de influência estabelecido graças aos predicados intrínsecos do líder ou chefe, que o convertem num ente superior diante daqueles que se acham sob suas ordens. Nesses termos, atento à descrição da personagem portadora de carisma, o sociólogo preocupa-se em identificá-la como a figura que reúne em si dons físicos e espirituais que saltam para a esfera sobrenatural e que por isso não são acessíveis a todo mundo. É fenômeno que emerge de dentro (do indivíduo) para fora (o ambiente), de que é exemplo, na sua corporificação mais pura, o herói, a liderança natural, sobretudo nascente em situações de crise. No ideário weberiano, a entidade dotada de carisma e o seu poder de domínio só conhecem determinações internas e limites próprios.

A dominação burocrática tem os elementos determinantes de sua estrutura baseados: a) no registro escrito das atividades de cada órgão necessárias à consecução dos fins; b) na distribuição estável e estrita da autoridade entre agentes encarregados da execução; c) na profissionalização desses agentes. Isto quer dizer que o tipo ideal de burocracia weberiano pressupõe uma composição de cargos ou empregos exposta com precisão em todas as suas minúcias. Segue, assim, uma ordem hierárquica com linhas de autoridade e responsabilidades delimitadas, normas e regulamentos para os atos oficiais, fatores, vale frisar, que coexistem com a seleção de pessoal sob o critério de qualificações técnicas ou profissionais, com a segurança no desempenho do cargo e a possibilidade de carreira. A impessoalidade nas relações, a divisão do trabalho, a rotinização de tarefas, e a racionalidade, mormente a racionalidade, são traços que perpassam toda a estrutura e a individualizam.

Os tipos ideais de ação social e de dominação de Weber são elementos essenciais para o entendimento do Modelo Multidimensional-Reflexivo proposto por Alves (2003). O modelo é constituído a partir de uma combinação dos componentes determinantes dos tipos ideais weberianos, que são reelaborados e considerados como um conjunto de variáveis (BARROS, 2007).

\subsection{O Modelo Multidimensional-Reflexivo}

Empenhado na missão de contribuir para o aperfeiçoamento da pesquisa organizacional e tendo como base as referências da sociologia weberiana, Alves (2003) objetiva, com o seu modelo, aprimorar e patrocinar um salto qualitativo no instrumental sociológico de análise das organizações, superando o primado das posições dualistas, do destaque exagerado da estrutura ou dos excessos cometidos ao papel do agente individual, entre outros fatores. A sua proposta alicerça-se em um percurso que propõe aportes teóricos interdisciplinares e dialógicos (ALVES, 2003).

O construto que recebe a denominação de Modelo de Organização MultidimensionalReflexivo (OMR) é erguido segundo a perspectiva em que o "sistema-organização" e o "agente individual" são considerados como dimensões articuladas e reciprocamente condicionantes, numa combinação que reclama abordagem interdisciplinar, sobretudo à base de conceitos originários da Sociologia e da Administração. Na visão do autor, com essa fórmula, estariam fornecidas ao OMR possibilidades mais amplas para servir de referencial em tarefas de análise das organizações empresariais. 
O desenho do OMR apresenta-se como o produto de um esquema de dupla entrada. De um lado, ao assumir componentes dos tipos ideais weberianos (o burocrático, o patriarcal e o carismático), que se manifestam através de mecanismos híbridos de regulação (controle utilitário ou controle normativo) no interior da empresa. De outro, ao incorporar circunstâncias temporais: o passado - hábitos e costumes consolidados na história da empresa, em que se predomina a administração patriarcal; o presente - experiência imediata e fluxo contínuo de atividades, tendo como principal representação a estrutura burocrática; o futuro - incorpora em partes a experiência passada, levando a reflexão para conceber a visão futura que se almeja, assentandose, em especial, na gestão com traços carismáticos. Convém destacar que esses elementos temporais, ao atuarem por sobreposição, acabam por determinar práticas internas e consagrar formas de gestão que, no final, reportam com maior ou menor dosagem aos tipos definidos por Weber (gestão fundada na racionalidade instrumental, ou em hábitos e costumes, ou em sentimentos afetivos).

Assim, conforme a visão de Alves (2003), e para exemplificar o último aspecto retratado acima, a estrutura burocrática, apesar de ter regras e rotinas cristalizadas no decorrer do tempo, constitui o tipo de organização em que sobressai o foco na atualidade. Em outras palavras, se a experiência da organização atém-se com maior intensidade ao tempo presente, então prevalecem modos de gestão calcados na racionalidade instrumental, configurando uma estrutura de perfil muito mais burocrático do que carismático ou patriarcal.

Daí a importância do "agente individual" dentro da perspectiva de sua interação com o "sistema-organização". Ambos, sem dúvida alguma, corporificam um complexo que se inscreve num "ambiente" dinâmico, mas é o "agente individual" a entidade que responde pelos movimentos (escolhas e decisões) muitas vezes decisivos para a vida e desenvolvimento da organização.

Esse protagonista é figura que Alves (2003) reconhece como Agente Organizacional Multidimensional-Reflexivo (AMR), um construto específico que não só observa a racionalidade, mas também a tradição e os sentimentos afetivos no proceder, em especial na condição de principal dirigente e detentor da propriedade da empresa. Ele é uma combinação de elementos do patriarca, do líder carismático e do burocrata, não atuando de maneira única e constante. $\mathrm{E}$ em função do modo como atua, podendo ser um AMR conservador (em que se mesclam os atributos do burocrata e do patriarca típicos, em que se destaca a necessidade de garantir ordem, costumes e estabilidade da organização), ou um AMR transformador (mistura de patriarca reformista com líder de traços carismáticos, com vistas a empreender inovações e mudanças), ou um AMR adaptador (personagem que sintetiza ou o burocrata flexível, ou o patriarca renovador, ou o líder com traços moderadamente carismáticos, possuindo comportamento mediador e buscando ajustar a empresa às novas demandas que surgem).

Com vistas a ensejar uma melhor análise das organizações no mundo real - pois este, de fato, é o objetivo maior que Alves (2003) pretende alcançar -, conjugando todos os fatores atrás relatados, três tipos estruturais híbridos de OMR foram propostos no modelo: o ordenativoconservador - em que se destacam a estabilidade, as regras e práticas orientadas pelos costumes e o culto ao preexistente; o liberativo-transformador - em que se focaliza a mudança, a flexibilidade e a inovação; o equiparativo-adaptador - em que predomina um equilíbrio entre mudança e conservação, flexibilidade e rigidez, autonomia e controle, inovação e rotina, correspondendo à estrutura-embrião do modelo. A organização que se aproxima do tipo 
equiparativo-adaptador é aquela em que se combinam os característicos da burocracia flexível, da liderança carismática atenuada e do patriarcado renovador, ingredientes esses associados à presença do AMR adaptador, que em geral priva de certa autonomia para agir no sentido de adequar a empresa a novas necessidades e demandas, por meio de uma gradual implementação de mudanças" (ALVES, 2003). O Quadro 1 demonstra as principais características dos três tipos estruturais trazidos pelo modelo.

Quadro 1: Características dos três tipos estruturais híbridos de OMR Fonte: Alves (2003).

\begin{tabular}{|c|c|c|}
\hline $\begin{array}{c}\text { Empresa } \\
\text { Equiparativo-adaptadora }\end{array}$ & $\begin{array}{c}\text { Empresa } \\
\text { Ordenativo-conservadora }\end{array}$ & $\begin{array}{c}\text { Empresa } \\
\text { Liberativo-transformadora }\end{array}$ \\
\hline Burocracia flexível & Burocracia rígida & Burocracia incipiente \\
\hline Patriarcado renovador & Patriarcado conservador & Patriarcado reformista \\
\hline $\begin{array}{c}\text { Liderança com traços } \\
\text { carismáticos mitigados }\end{array}$ & $\begin{array}{c}\text { Liderança descarimatizada } \\
\text { (carisma objetivado) }\end{array}$ & $\begin{array}{c}\text { Liderança com traços } \\
\text { carismáticos }\end{array}$ \\
\hline
\end{tabular}

Há indicadores que ajudam a identificar a organização dentre os três tipos estruturais híbridos de OMR. São eles: ambiente e relações interempresariais - que tem como foco analisar o ambiente externo à organização; características estruturais e dispositivos de coordenação que tem como propósito verificar a estrutura organizacional, seus processos e relações; características do agente e relacionamentos internos - que objetiva examinar a atuação do agente e as relações internas desenvolvidas entre as pessoas; natureza das tarefas e sistema técnico-operacional - que aborda a forma como as tarefas são realizadas e o uso de tecnologias. Esses indicadores são justamente os que foram usados na descrição do estudo de caso empreendido neste artigo, para realização de posterior enquadramento das organizações estudadas como determinado tipo estrutural de OMR.

A Figura 1, que se segue, traz uma representação dos principais aspectos trazidos pelo Modelo de OMR de Alves (2003).

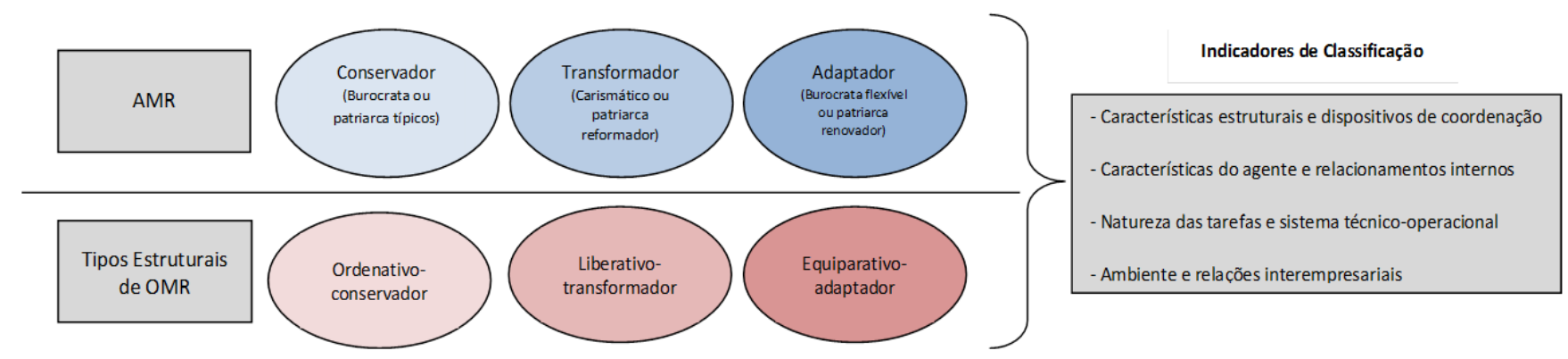

Figura 1: Esquema representativo aspectos do Modelo de OMR Fonte: Baseado em Alves (2003).

$\mathrm{Na}$ concepção de Alves (2003), enquanto estrutura-base do modelo, o formato equiparativo-adaptador constitui um tipo em torno e a partir do qual se pode discutir a casualidade de migração para uma das duas outras formas estruturais (a ordenativoconservadora ou a liberativo-transformadora). Tal trajetória, na visão do autor, se daria sob a égide de um contínuo processo de organização - interações - reordenamento, sem que, ao cambiar de um estado para outro, a empresa o faça mediante uma completa substituição de seus traços originais ou primários. 
Quanto ao agente e seus relacionamentos, o AMR adaptador pode estar representado por diversos protagonistas e situado em diversas posições da estrutura organizacional. É agente que procede à luz de uma ideia multidimensional de tempo, assim levando em conta a história empresarial (passado), os fatos correntes (presente) e cenários prospectivos (futuro), de sorte a identificar necessidades de mudanças e formular alternativas para materializá-las, sempre adaptando a organização a novas situações ambientais.

\section{METODOLOGIA}

A estratégia de pesquisa escolhida para a realização deste trabalho é o estudo de caso. Essa estratégia caracteriza-se pelo fato de o pesquisador poder explorar e detalhar profundamente o fenômeno que está estudando, o qual pode ser representado por um evento, uma atividade, um processo, um ou mais indivíduos (CRESWELL, 2010). Para realização do estudo de caso, o objeto tomado para investigação foi uma holding, aqui retratada como Grupo Alfa Participações Ltda., que abarca duas empresas familiares, configuradas neste artigo como Empresas Beta e Gama, ambas sediadas no estado de Pernambuco.

A pesquisa assenta-se, essencialmente, em bases qualitativas, já que não tem o propósito apenas de enumerar ou medir eventos, mas sim de entender determinada organização familiar, a partir dos entes envolvidos na situação estudada, por meio de dados descritivos obtidos através de contato direto do investigador com o objeto de estudo (NEVES, 1996). Além disso, a pesquisa traz na sua configuração um enfoque analítico, ao fazer uso de um modelo de análise organizacional, e descritivo, ao expor as características de uma determinada população ou fenômeno ou observar a ocorrência de associações entre variáveis (GIL, 2006). As três técnicas de coletas de dados que foram utilizadas no estudo foram: pesquisa documental, entrevistas e observação não-participante.

Na visão de Gil (2002), a pesquisa documental é aquela que faz uso de materiais de diversas naturezas, que não se valeram de um tratamento analítico, ou que podem ser reelaborados de acordo com os objetos da pesquisa. Para a investigação proposta, foram acessados o site e documentos da empresa tais como contrato social, relatórios, arquivos e tabelas estatísticas, que foram extremamente úteis para o levantamento de informações acerca do objeto de estudo.

A entrevista é definida por Lima (2004) como uma conversa de caráter profissional ou acadêmico, entre duas ou mais pessoas, a fim de se obter informações dela(s) sobre determinado assunto. Os três tipos de entrevistas qualitativas mais importantes são: a entrevista conversacional livre, a baseada em roteiro e a padronizada aberta (GODOI; MATTOS, 2006). As duas entrevistas empreendidas seguiram um roteiro semi-estruturado, ou seja, identificam-se como uma entrevista padronizada aberta, e foram realizadas com o sócio-proprietário da empresa e com o CEO (chief executive office) responsável pela holding. Para o registro da entrevista, utilizou-se um gravador, de modo que esses registros posteriormente foram transcritos. A utilização desse método permitiu um melhor conhecimento acerca do funcionamento da holding como um todo e de toda a sua estruturação, trazendo informações extremamente valiosas. 
A observação é um método adequado em análises não verbais, em que objetiva-se verificar condutas instituídas e códigos de comportamentos, podendo ocorrer tanto através de uma observação participante, quando há uma participação do pesquisador na vida coletiva estudada, quanto através de uma observação não participante, quando o investigador observa determinado contexto do exterior (QUIVY; CAMPENHOUDT, 1998). Neste estudo foi conduzida uma observação não-participante, que se deu por meio do registro de ações e do comportamento dos funcionários da organização durante o expediente. Mesmo sem haver uma interação profunda com o dia-a-dia desses funcionários, o pesquisador conseguiu ter acesso aos principais departamentos da empresa, inclusive, aos seus setores de produção e armazenamento de produtos, o que possibilitou a observação e o registro de parte da rotina da holding. As observações mostraram-se úteis para comprovar algumas informações obtidas a partir dos documentos acessados e das entrevistas.

A análise dos resultados da pesquisa, enfim, foi realizada por meio da técnica de análise de conteúdo, a partir dos registros e das transcrições obtidas através da pesquisa documental, da observação não-participante e da entrevista realizada. A análise de conteúdo refere-se a uma técnica em que é feita a decomposição de determinado discurso e identificação de unidades de análise ou grupos de representações, para que possa ser realizada a categorização de fenômenos, tornando possível uma reconstrução de significados que possam permitir um entendimento mais apurado de interpretação da realidade do material estudado (SILVA; GOBBI; SIMÃO, 2005).

A parte analítica da pesquisa, assim, se deu por meio de criação de categorias, em que os dados puderam ser distribuídos, o que permitiu a análise e interpretação das informações coletadas. Vale salientar que as categorias utilizadas pelo pesquisador foram criadas tendo como base o modelo analítico utilizado na pesquisa, o que possibilitou, ao material coletado, o seu cuidadoso enquadramento para posterior processo interpretativo. Essas categorias, trazidas por Alves (2003) como indicadores, abrangem: ambiente e relações interempresariais; características estruturais e dispositivos de coordenação; características do agente e relacionamentos internos; natureza das tarefas e sistema técnico-operacional.

\section{RESULTADOS E DISCUSSÕES}

\subsection{Histórico do Empreendimento}

A partir do acesso ao site e aos documentos da organização estudada, tornou-se possível a obtenção de um entendimento geral da historia do Grupo Alfa e de suas duas empresas (Beta e Gama), conforme se buscou descrever a seguir.

A Empresa Beta foi criada na década de 70 em Pernambuco, de início, atuando na representação de grandes fabricantes de papel de jornal e de papeis revestidos. Ainda na linha da representação, celebra, no começo da década de noventa, um contrato com outras duas empresas do ramo, ampliando, dessa forma, o volume do seu trabalho no ramo de papéis. $O$ ano de 2000 marca uma profunda inflexão na vida da empresa. Atenta à evolução do mercado nordestino, a Empresa Beta abandona o segmento da representação, deslocando seus esforços para atividades de estocagem e revenda. É o início de uma trajetória de expansão, assinalada por contratos com grandes fornecedores do ramo papeleiro mundial, e, pouco depois, em 2003, pelo 
início da importação e distribuição de tintas para rotativas. Atualmente, o foco da empresa continua sendo a comercialização de papel de imprensa para organizações jornalísticas privadas e oficiais, setor responsável por cerca de $80 \%$ do seu faturamento.

A Empresa Gama, por sua vez, foi fundada em 2000, também em Pernambuco. Suas operações restringiam-se, de partida, à industrialização e à comercialização de papéis, mediante o aproveitamento de sobras e seleção de avarias, então convertidas em cortes especiais destinados ao mercado gráfico. Crescendo, passou a dedicar-se não só à importação e distribuição de papel, como à venda de materiais de escritório e escolar e de artigos de papelaria em geral, abrindo um novo setor de comércio. Decorridos aproximadamente cinco anos desde a sua fundação, com o advento de uma unidade interna e específica de negócios, ingressou no mercado de informática, de pronto firmando-se no segmento de vendas de mídias e periféricos para computadores. A progressão das atividades da empresa no ramo do papel é evidenciada pelo conjunto de parceiros-fornecedores que hoje ostenta, elenco em que se incluem organizações de grande porte nacionais e internacionais. Nesse ramo, o foco da Empresa Gama é a distribuição para a indústria gráfica, fonte que responde por algo em torno de $85 \%$ do seu faturamento.

A Empresa Gama e a Empresa Beta, empresas de natureza familiar, unidades distintas, juridicamente separadas, são idealizações dos Fundadores $X$ e $Y$, sempre associados, unidos por laço de parentesco afim. O primeiro, inclusive, portador de larga experiência adquirida quer como funcionário, quer no exercício de cargos de confiança em grandes grupos nacionais. Com o óbito do Fundador Y, em 2004, é o Fundador X quem de fato assume o encargo pelos rumos das duas unidades, quem projeta coligá-las à base de um novo modelo societário e capaz, a um só tempo, de resolver o problema sucessório dentro das mesmas. Em 2008, com efeito, é formalmente instituído o Grupo Alfa Participações Ltda., dando formato a uma holding, abarcando a Empresa Beta e a Empresa Gama, perfazendo empreendimento que conta com a participação acionária das famílias em cada um dos seus ramos de negócios e regido pela distribuição do capital social expressa no quadro adiante.

Quadro 2: Composição do Capital Social em 2008

Fonte: Relatórios da Administração da Empresa Beta e Empresa Gama (2008).

\begin{tabular}{|c|c|c|}
\hline Empresas & Acionistas & Participação (\%) \\
\hline \multirow{3}{*}{ Empresa Beta } & Alfa Participações Ltda. & 99,99 \\
\cline { 2 - 3 } & X Junior & 0,01 \\
\cline { 2 - 3 } & Total & 100,00 \\
\hline \multirow{3}{*}{$\begin{array}{c}\text { Empresa } \\
\text { Gama }\end{array}$} & Alfa Participações Ltda. & 99,99 \\
\cline { 2 - 3 } & Y Junior & 0,01 \\
\cline { 2 - 3 } & Total & 100,00 \\
\hline
\end{tabular}

$X$ Junior e $Y$ Junior, filhos dos Fundadores, representando suas respectivas famílias, desempenham funções-chave, remuneradas, nas unidades em que detêm participação acionária, as quais, permanecem operando normalmente nos campos que lhes são próprios. A holding é comandada por um executivo-chefe (CEO), com visível autoridade que se estende sobre as áreas comercial e administrativo-financeira. No entanto, no fundo, é sob a liderança do Fundador do Grupo, representado por $\mathrm{X}$, que todos os principais movimentos das empresas acontecem, de forma que o mesmo encontra-se sempre presente no dia a dia dos negócios, intitulando-se, a si mesmo, uma espécie de "consultor" da Empresa Beta e da Empresa Gama. Justificada pelo seu conhecimento, teórico e prático, reconhecida experiência no ramo e elevada capacidade de 
trabalho, a ascendência do "consultor" sobre os demais conselheiros-acionistas do empreendimento é notória.

\subsection{Especificações Relativas ao Modelo}

Todos os detalhamentos realizados a seguir, sobre o Grupo Alfa Participações Ltda., que por sua vez abrange as empresas Beta e Gama, baseiam-se em informações obtidas através do site, dos documentos, da observação e das entrevistas realizadas. Nesse sentido, tais detalhamentos buscam abordar cada um dos indicadores do Modelo OMR.

\subsubsection{Ambiente e Relações Interempresariais}

A Empresa Beta concentra suas atividades na Região Nordeste, seu principal mercado de distribuição, embora, recentemente, o tenha expandido através do fornecimento de papel de jornal a imprensas oficiais do Sudeste e Centro-Oeste do Brasil. Essa expansão aumentou o faturamento anual da empresa em 2008 em 51\% em relação ao ano anterior. Tanto no âmbito do Nordeste, quanto nas duas outras regiões acima ventiladas, trata-se de um mercado em que a competição é intensa, valendo frisar, nesse aspecto, que a Empresa Beta rivaliza na conquista de clientes com boa fração das mesmas empresas que antes representava nos primeiros tempos da sua existência. Nas vendas, a unidade mantém três agências incumbidas de cobrir os alguns estados do Nordeste.

A Empresa Gama atende as regiões Norte e Nordeste. Mantém uma agência em São Paulo para suprir clientes do Sul, Sudeste e Centro-Oeste do Brasil, criada em 2008, cujo faturamento já representa cerca de $30 \%$ da receita total da empresa. Tendo como principais produtos variados tipos de papéis, que se somam a outros itens, o faturamento global da Empresa Gama em 2008 exibiu um incremento de $65 \%$ quando comparado ao do ano de 2007 . Opera, também, num mercado fortemente competitivo, disputando clientes, especialmente ao nível da indústria gráfica, com organizações de grande porte, nacionais ou estrangeiras, atuantes no ramo.

No cenário comercial do papel a Empresa Beta e a Empresa Gama, juntas, inscrevem-se entre as cinco maiores distribuidoras do país, conforme avaliações dos entrevistados. Sobre o crescimento da organização, um dos entrevistados fez o seguinte comentário: “...o crescimento da nossa organização é decorrente da grande aproximação que temos com os fornecedores e clientes que nos cercam, o que nos permite estar acompanhando tendências, mudando e inovando...". Assim, é através dessa aproximação com os atores do ambiente externo, que os executivos do grupo relataram vislumbrar novas oportunidades de negócios e enfrentar eventuais mudanças nesse contexto.

Além disso, embora se tenha a consciência de que as relações no âmbito do empreendimento, em escalões superiores, ocorram à base de uma evidente pessoalidade e afetividade, os entrevistados relataram a existência de cuidados especiais para que isso não venha a quebrar o sistema hierárquico vigente. Sobre esse aspecto, foi declarado na entrevista que apesar de existir uma estrutura hierárquica na organização, essa hierarquia não impede ou dificulta os relacionamentos que são desenvolvidos com os atores com quem essa organização se relaciona.

\subsubsection{Características Estruturais e Dispositivos de Coordenação}


O Grupo Alfa Participações Ltda., segundo os entrevistados, tem uma estrutura enxuta e descentralizada em vários aspectos ligados à operação. $O$ corpo de funcionários não vai muito além de um número em torno de cem pessoas. O poder de decisão, todavia, apenas em parte é descentralizado, e, mesmo assim, obedece a limites pré-estabelecidos, principalmente em se tratando de aquisições ou vendas, já que de acordo com os entrevistados a alta gestão costuma estar ciente do funcionamento geral da organização, participando diretamente das decisões que considera serem estratégicas e que são relevantes ao futuro do Grupo.

Toda a atividade fiscal/tributária é centralizada na sede (emissões de notas fiscais etc), de onde existe uma forte ênfase no sentido da formulação e aplicação de dispositivos de controle com elevada inspiração econômica. Os entrevistados destacaram que é na sede que se tem o controle geral do Grupo, com o propósito centralizar essa atividade e de garantir melhores resultados para a organização. Os relatórios da administração, até os mais triviais, constituem uma prova desse controle, uma vez que são detalhados de estatísticas e índices econômicos e financeiros, sistematicamente atualizados em curtos períodos.

Poder-se-ía afirmar que, pelas informações levantadas nesta pesquisa, o Grupo estudado forma um tipo de burocracia flexível, conforme o Modelo de Alves (2003), já que, de acordo com os entrevistados, se encontra nas mãos de um indivíduo que tem um perfil patriarcal, contudo renovador. Isso pode ser constatado através do relato obtido nas entrevistas que, durante a crise financeira internacional que se iniciou no último trimestre de 2008, o papel exercido por esse indivíduo, sintetizado na figura do Fundador $\mathrm{X}$, foi de fundamental importância para garantir ao empreendimento o mínimo de perdas e a manutenção da rentabilidade dos negócios em patamares satisfatórios. De modo que planos de expansão foram adiados, volumes de compras foram reprogramados, operações de hedge foram revistas, assim como aplicações em derivativos, entre outras medidas, tudo para adequar a Empresa Beta e a Empresa Gama a uma nova realidade de mercado. A crise, vale dizer, de certo modo foi transformada numa oportunidade para o Grupo buscar, no mercado, pessoal com alto grau de qualificação para compor os seus quadros.

\subsubsection{Características do Agente e Relacionamentos Internos}

A crise econômica mundial, que atingiu seu ápice em 2008, de acordo com as informações das entrevistas, foi uma razão basilar para que o "consultor" e patriarca (Fundador X) continuasse firme na orientação dos rumos das empresas, adiando mais uma vez o seu afastamento voluntário. O processo de constituição da holding, iniciado em 2004, estava no seu apogeu, a poucos passos da materialização. E embora esse processo não fosse impregnado de modificações brutas e profundas, não há como negar que as empresas estavam vivendo um momento especial e delicado nas suas trajetórias.

Foi exatamente nesse momento, de acordo com os entrevistados, que se fez notar o poder de liderança e carisma reunidos na pessoa do Fundador $X$, remetendo, sem dúvida alguma, ao paradigma do AMR adaptador descrito por Alves (2003, p.153): “... uma combinação de patriarca renovador, líder empresarial com traços carismáticos mitigados e burocrata flexível". Nele observa-se, com efeito, o empenho fortalecer o comprometimento dos indivíduos com a organização, exemplo que transfere para os diretores e executivo-chefe do empreendimento, e que foi decisivo, no começo e transcurso da crise, para diminuir tensões entre os funcionários. 0 Grupo manteve o seu histórico sistema de bonificações anuais, além da prática de incentivo à 
qualificação profissional, inclusive mediante o subsídio pessoal concedido para pagamento de mensalidade em universidades e em outros cursos, o que, como há de se convir, decerto implicou algum sacrifício financeiro do empreendimento. Nesse sentido, um dos entrevistados fez questão de destacar a importância da qualificação dos profissionais do Grupo: “...queremos ter em nosso corpo profissional, pessoas motivadas, que busquem se atualizar e que tragam novas competências para a organização".

Ao lado do comprometimento funcionário/organização, também foi frisado pelos entrevistados, que existe um grande comprometimento do Grupo na relação organização/comunidade, que se traduz em ênfase à função social que deve cumprir uma empresa. No exemplo da Empresa Beta e Empresa Gama, essa função se corporifica no apoio que presta à escola pública, localizada em uma comunidade próxima à sede de ambas as unidades. Há quatro anos, as empresas ocupam-se da manutenção e fornecimento de artigos escolares a 350 crianças que lá estudam. Em 2008 foram doados computadores à escola e montada uma moderna estrutura de rede para conexão à Internet.

A partir das entrevistas, ficou claro, também, que para o Fundador $X$, e este é um lema de que não abre mão e que faz questão de disseminar, que a chave do sucesso do Grupo depende em grande medida de dois fatores básicos: a) união das famílias e zelo, sobretudo do lado daqueles que exercem funções-chave na estrutura, pelos valores, missão e objetivos das empresas; b) trabalho, disciplina e muita dedicação. Nessas afirmações, provavelmente, encontram-se embutidos os sentimentos de maior peso então adquiridos pelo patriarca ao longo de 30 anos de vivência no seu ramo de negócio.

\subsubsection{Natureza das Tarefas e Sistema Técnico-Operacional}

Com seus focos orientados para a distribuição de papel de jornal e de outros tipos, a verdade é que as empresas lidam com uma pauta relativamente diversificada de produtos. A constituição e preservação de redes fornecedores-empresas e de redes empresas-clientes são tarefas que requerem habilidades específicas, segundo os entrevistados.

Os entrevistados também frisaram que a compra, transporte, estocagem e abastecimento da clientela, por outro lado, exigem uma eficiente logística. A Empresa Gama, por exemplo, para melhor atender a região Sul, vale-se dos portos dessa região, onde utiliza os serviços de um operador terceirizado. Coisa igual ocorre nas cargas concentradas no porto do Estado de Pernambuco, que embora próximo dos armazéns da empresa, o que possibilita certas facilidades e custos mais baixos, não elimina a necessidade da aquisição de equipamentos e o concurso de alguns serviços terceirizados.

Tudo isso confirma a existência de um palco de operações com algum grau de complexidade e, por consequência, pessoal treinado para tanto. É, assim, que uma das mais sentidas preocupações dos dirigentes, segundo os entrevistados, seria a formação de um quadro de pessoal qualificado, política interna rigorosamente seguida através de um fluxo permanente de investimentos em incentivos motivacionais e educacionais. Investimentos que também alcançam o aporte tecnológico voltado para a modernização das empresas, de que é testemunha o uso de um avançado sistema informacional integrado para a operacionalização e controle das atividades empresariais nos seus mais diferentes departamentos. 
Na palavra dos gestores, as empresas são submetidas periodicamente a avaliações de desempenho, em geral executadas abrangendo aspectos referentes à solidez, estabilidade e segurança econômica do empreendimento, pessoal, áreas funcionais com suas correspondentes atividades e fluxos operacionais.

\section{CONCLUSÃO}

Alves (2003) define uma organização empresarial do tipo equiparativo-adaptador como aquela cujos traços de maior relevo combinam-se na existência de uma burocracia flexível, uma liderança com traços carismáticos mitigados e patriarcado renovador. Passando em revista os achados da pesquisa, vê-se que o Grupo Alfa Participações Ltda., objeto deste estudo de caso, enquadra-se quase que totalmente nessa definição.

Como ficou notificado nas seções anteriores, o Grupo pretende-se um empreendimento moderno, competitivo, sintonizado com o ambiente e preparado para realizar as mudanças necessárias para sua adaptação a situações futuras. E de fato o é. Tanto a Empresa Beta, quanto a Empresa Gama, são empresas que, nos seus ramos, se não se afiguram exemplares, quando menos se aproximam disso. As manifestações daquilo que se denomina burocracia flexível são percebidas em todas as faces dessas organizações, da hierarquia à impessoalidade das relações em níveis de baixa intensidade.

Unidades tipicamente familiares, passaram por um recente processo de reordenamento que culminou numa holding, embora sem afetar a individualidade de cada empresa ou engessar procedimentos internos. O empreendimento é comandado por um executivo-chefe, e em todos os setores intermediários e de direção superior, transparece a presença de pessoas qualificadas, exercendo funções-chave, qualificação que se exige até aos membros pertencentes às famílias proprietárias dos negócios.

No entanto, é inegável que as principais decisões do Grupo passam pela avaliação e pelo crivo de um personagem que, vivenciando por dentro as duas empresas, pertencendo a uma das vertentes familiares e na condição de fundador de ambas as unidades, espalha e exerce uma liderança inconteste sobre todo o conjunto, o Fundador X. Não se trata de uma liderança nem impetuosa, nem radical, mas, pelo contrário, de um gênero que, ao transmitir confiança, força moral, conhecimento de causa e capacidade de trabalho, de pronto conquista o respeito dos funcionários. Nesse personagem mesclam-se, ainda na definição de Alves (2003), elementos de um carisma atenuado e de um patriarca renovador, que na verdade funcionam como um esteio, principalmente para aqueles que exercem funções estratégicas dentro das empresas.

Se ocorre algum distanciamento do paradigma proposto por Alves (2003) e o caso estudado, não se pode dizer que seja algo relevante. Pode-se, sim, estranhar a presença de um único líder, ou pelo menos de uma única liderança e com o porte como a que foi observada no Fundador $X$, sem que isso haja implicado na verificação de um estado contraditório entre o modelo e a realidade. A organização centrada em um líder é aquela em que sobressaem aspectos próprios do carisma que, levado ao máximo pelo indivíduo, imputaria ao negócio uma boa dose de personalismo. Todavia, não é este o desenho que se vislumbra na Empresa Beta e na Empresa Gama, pois que na figura da liderança do Fundador X, há muito mais ingredientes patriarcais do que carismáticos, e muito mais elementos burocráticos do que patriarcais. Por outro lado, sendo 
o tipo equiparativo-adaptador apenas um modelo, dele não se esperaria uma leitura da realidade capaz de abarcá-la em toda a sua plenitude.

Considerando que são dois os atributos fundamentais de um modelo, ou seja, sua capacidade de explicar e sua capacidade de predizer, vê-se que no construto oferecido por Alves (2003) ambas as propriedades encontram-se presentes de modo muito claro. Os esquemas e conceitos disponibilizados revelaram-se eficazes em relação ao objeto estudado. Quanto à predição, diga-se que as variações internas do tipo-base (equiparativo-adaptador), bem como as alternativas de transição apresentadas pelo autor também mostraram-se recursos teóricos de grande valia. O caso do Grupo Alfa Participações Ltda., por exemplo, se enquadraria muito bem num espaço intermédio entre a situação original e a primeira variante do tipo-base, isto é, pronunciando-se como uma organização caracterizada por uma burocracia menos flexível, preservados os traços do carisma mitigado e do patriarcado renovador. Mas esta seria apenas uma hipótese.

Por enquanto, à vista dos resultados colhidos com a pesquisa, o que se destaca e o que é plausível afirmar sobre o Grupo, é que ele participa de um ambiente competitivo e dinâmico; que ostenta uma hierarquia de procedimentos que convive com relações pessoais e vínculos afetivos originários da natureza familiar do empreendimento; que há relações funcionais estáveis e uma boa dose de regularidade nas operações empresariais; que os dispositivos de controle enfatizam sobremaneira os aspectos econômicos; e que se desenvolve, no interior das empresas, uma política de pessoal fortemente marcada pela preocupação com a qualificação e a valorização do capital humano.

Além disso, o Grupo tem na figura de seu sócio-proprietário, Fundador X, um consultor que atua através de uma forte liderança nas principais atividades e decisões das duas empresas, operando, segundo o modelo de Alves (2003) como um AMR adaptador, já que tem a preocupação de adaptar as empresas para que as mesmas se perpetuem e enfrentem a competitividade do mercado. Isso pode ser constatado, essencialmente, na transformação do Grupo, empreendida pelo Fundador $\mathrm{X}$, em holding, que teve como propósito resolver a questão sucessória das duas empresas da família.

Isto posto, sem dúvida alguma, todos os característicos retratados no presente artigo, permitem o enquadramento do Grupo Alfa Participações Ltda. como uma organização, de fato, equiparativo-adaptadora, à luz do modelo formulado por Alves (2003). Este estudo apresenta algumas limitações, dentre as quais se encontram: análise do Modelo OMR, basicamente, a partir da perspectiva de dois executivos da alta gestão; necessidade de maior aprofundamento dos indicadores utilizando todos os aspectos abrangidos pelo Modelo de Alves (2003); dificuldade no agendamento das entrevistas e da visita à organização, bem como interrupções durante as entrevistas, em virtude do tempo escasso dos entrevistados. A título de direcionamentos futuros, derivados da pesquisa, pode-se destacar a necessidade de realizar estudos como esse em outras organizações que não tenham o perfil familiar, de modo a realizar comparações entre os resultados.

\section{REFERÊNCIAS BIBLIOGRÁFICAS}

1. ALVES, Sérgio. Racionalidade, carisma e tradição nas organizações empresariais 
contemporâneas. Recife: Editora UFPE, 2003.

2. ANTONIALLI, L. M. Problemas de sucessão e a sobrevivência das empresas familiares. In: SEMINÁRIOS EM ADMINISTRAÇÃO, 1998, São Paulo. Anais... São Paulo: FEA/USP, 1998. 1 CDROM.

3. BARROS, Daniel Lins. Análise de uma organização penitenciária feminina à luz do modelo multidimensional-reflexivo. Dissertação apresentada no Programa de Pós-Graduação em Administração na Universidade Federal de Pernambuco, 2007.

4. CAMPOS, L. J. \& MAZZILLI, C. Análise do processo sucessório em empresa familiar: um estudo de caso. Anais do XXII Encontro Nacional da Associação Nacional de Programas de PósGraduação em Administração, 1998. Disponível em CD-ROM.

5. CORREIA, Milka Alves. Análise de uma organização hospitalar à luz do modelo multidimensional-reflexivo de Alves (2003). Dissertação apresentada no Programa de PósGraduação em Administração na Universidade Federal de Pernambuco, 2007.

6. CRESWELL, J. Projeto de pesquisa: métodos qualitativo, quantitativo e misto. Porto Alegre: Bookman, 2010.

7. GIL, A.C. Como classificar as pesquisas? In: Como elaborar projetos de pesquisa. 4. ed. São Paulo: Atlas, p. 44-45, 2002.

8. GIL, Antônio Carlos. Métodos e técnicas de pesquisa social. São Paulo: Atlas, 2006.

9. GODOI, C. K.; MATTOS, Pedro L. C. L.de. Entrevista qualitativa: instrumento de pesquisa e evento dialógico. In: Pesquisa qualitativa em estudos organizacionais: paradigmas, estratégias e métodos. GODOI, C. K.; BANDEIRA-DE-MELO, R.; SILVA, A. B. da.; (org). São Paulo: Saraiva, 2006. p.301-323.

10. GRZYBOVSKI, D.; TEDESCO, J. C. Empresa familiar $\mathrm{x}$ competitividade: tendências e racionalidades em conflito. Revista Teoria e Evidência Econômica, Passo Fundo, v. 6, n. 11, p. 37-68, nov. 1998.

11. LETHBRIDGE, Eric. Tendências da empresa familiar no mundo. Revista do BNDES, n. 7, Brasília, 1997. Disponível em: http://www.bndes.gov.br. Acesso em: 20 set. 2012.

12. LIMA, Manolita C. Tipos de pesquisa e técnicas de coleta de materiais - a pesquisa de campo: observação direta intensiva - realização de entrevistas In: . Monografia: a engenharia da produção acadêmica. São Paulo: Saraiva, 2004.

13. MACÊDO, Kátia B. Cultura, poder e decisão na organização familiar brasileira. Revista de Administração de Empresas - RAE-eletrônica, v. 1, n. 1, jan./jun. 2002. Disponível em: http://www.rae.com.br/eletronica. Acesso em: 09 dez. 2012.

14. NEVES, J. L., Pesquisa qualitativa: características, usos e possibilidades. Cadernos de pesquisas em administra-ção, São Paulo, v. 1, n. 3, p. 103-113, 2 sem. 1996.

15. PEREIRA, Fernanda Cristina Barbosa. Administração estratégica nas Universidades federais: um estudo de caso na Universidade Federal de Santa Catarina. Florianópolis, 1999. Dissertação apresentada no Programa de Pós Graduação em Engenharia de Produção, Universidade Federal de Santa Catarina. Disponível em: http://teses.eps.ufsc.br/defesa/pdf/3656.pdf. Acesso em: 20 jun. 2012.

16. QUIVY, R; CAMPENHOUDT, L. V. Manual de Investigação em Ciências Sociais. 2 ed. Lisboa: 
Gradiva; 1998.

17. SILVA, C. R.; GOBBI, B. C.; SIMÃO, A. A. O uso da análise de conteúdo como ferramenta para pesquisa qualitativa: descrição e aplicação do método. Organizações Rurais e Agroindustriais. Revista Eletrônica de Administração da UFLA. Lavras-MG, v. 7, n. 1, p. 70-81, jan/abr 2005.

18. SOARES, J.; MACHADO, A.C.; MAROCCO, B. Gestão em família. Pequenas Empresas Grandes Negócios. Rio de Janeiro, v. 9, n 107, p:30-35, dezembro 1997.

19. TOSO JUNIOR et al. Alguns aspectos da administração familiar no Brasil. Revista Reverte, 2010.

20. WEBER, Max. Economia e sociedade. Revisão técnica de Gabriel Cohn. Brasília: Ed. UNB, 1999, v. 2. 